\title{
VIDEO ENDOSCOPIC INGUINAL LYMPHADENECTOMY (VEIL) FOR VULVAR MALIGNANT MELANOMA, AS AN ALTERNATIVE TO SENTINEL LYMPH NODE.
}

\section{Serrano O*, Vieira S **, Santana D*, García A*, Bonilla C*, Luna J*.}

${ }^{*}$ Gynecologist Oncologist, Clínica Colsanitas, Department of Oncology Gynecology. Bogotá, Colombia.

${ }^{* *}$ Resident of Gynecology and Obstetrics, Fundación Universitaria Sanitas, Bogotá, Colombia.

\section{OBJECTIVE}

Vulvar malignant melanoma (VMM) is a rare type of cancer accounting for $5 \%$ of all vulvar malignancies. Surgical treatment consists of wide local excision plus elective lymph node dissection (ELND) or sentinel lymph node (SLN). VEIL is an alternative approach for the radical resection of inguinal lymph nodes, which can reduce the morbidity of the ELND without compromising the therapeutic efficacy. We show the surgical procedure VEIL for VMM.

\section{METHODS}

70-year-old woman with ulcerated malignant melanoma of $1.5 \mathrm{~cm}$, central, vertical growth, Breslow 8 $\mathrm{mm}$, without lymphovascular or perineural invasion, with negative PET/SCAN for metastatic lesions, radical hemivulvectomy plus bilateral SLN was made, obtaining mapping only from the right sentinel node, therefore, VEIL was performed on the left side.

\section{Figure 1}

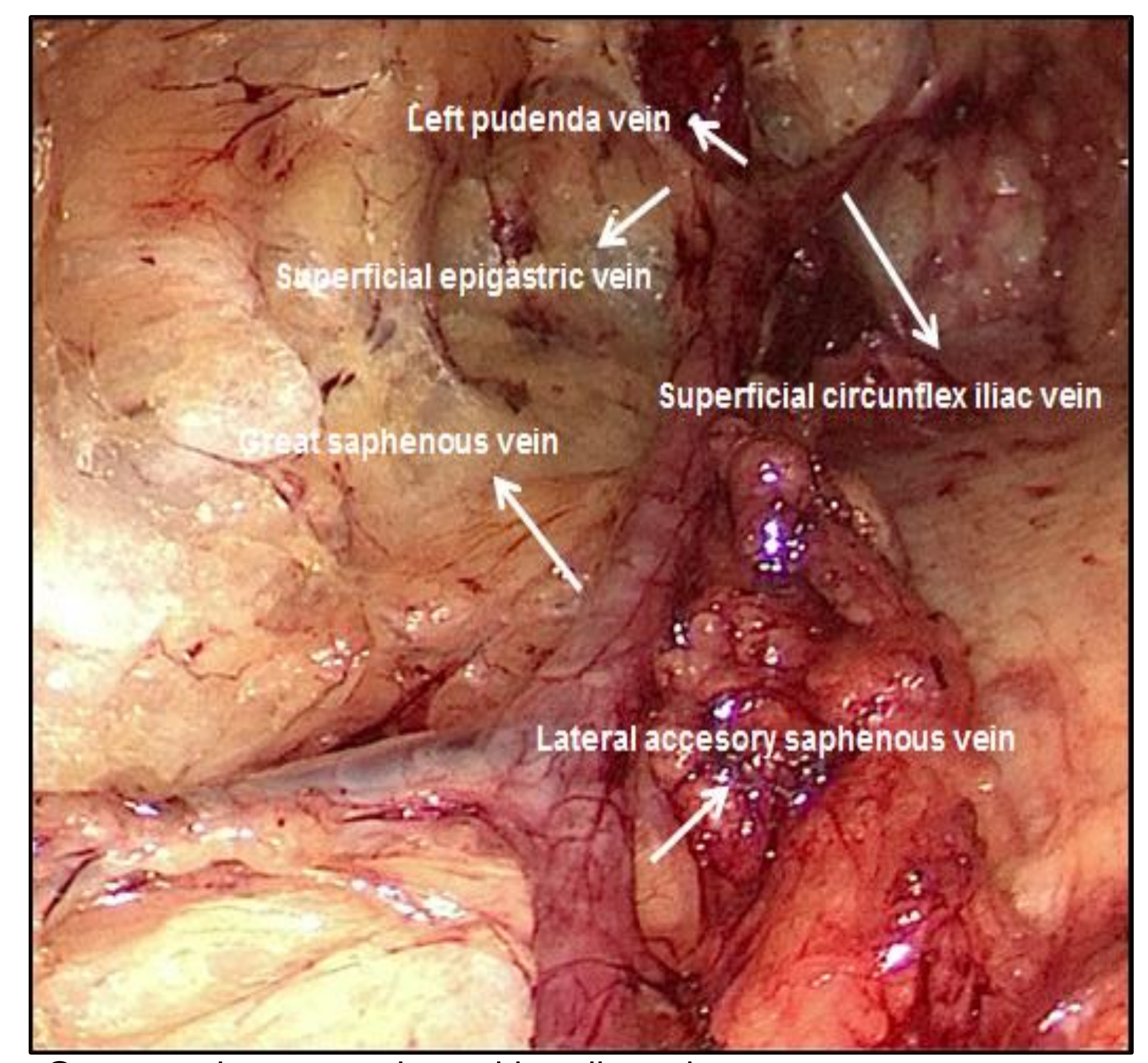

Great saphenous vein and its tributaries

\section{Figure 2}

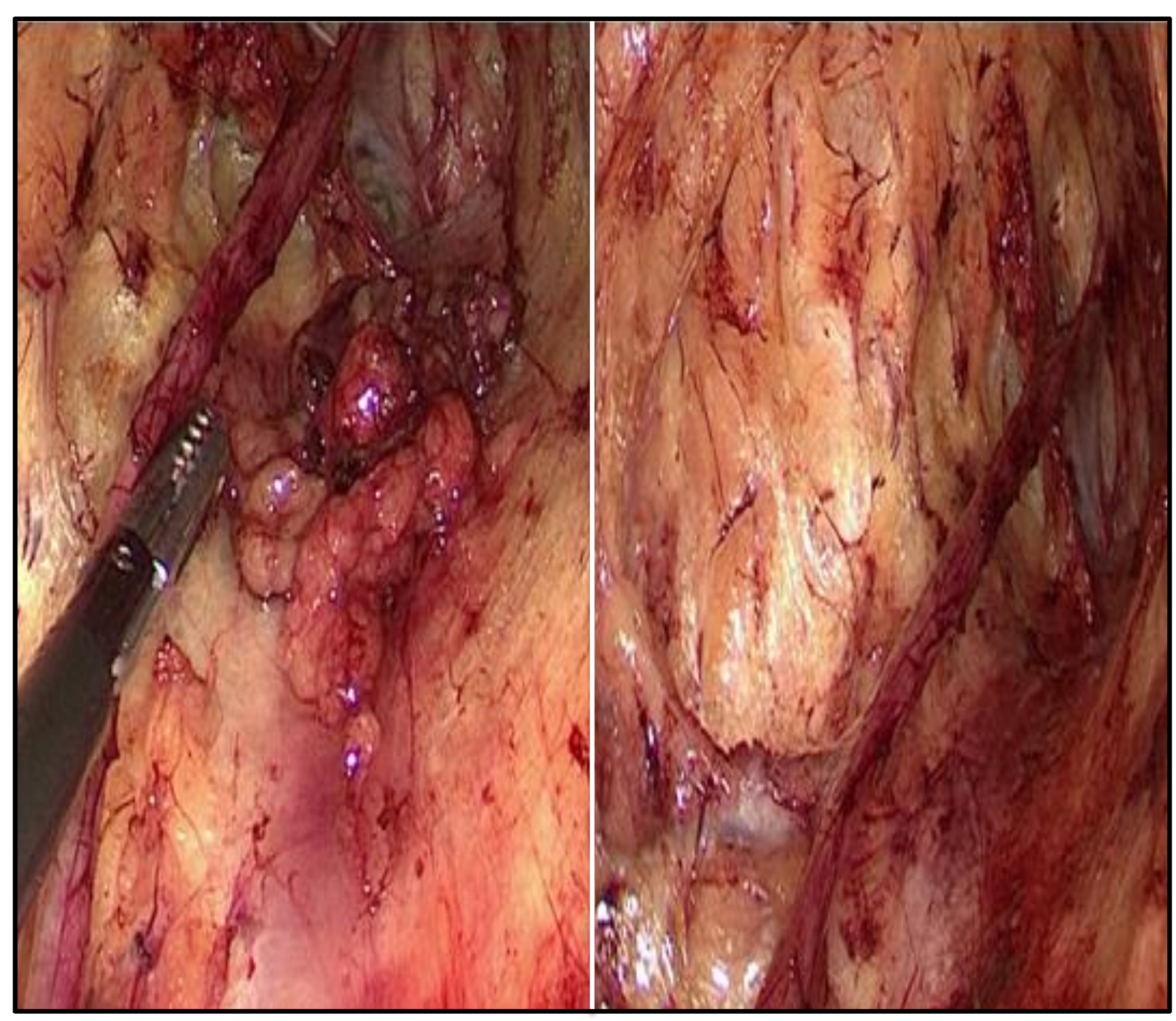

Before and after resection of the inguinal lymph nodes

\section{RESULTS}

Previous infiltrate with technesium-99, we detected with gamma sonda right inguinal sentinel lymph node and was resected. Then, we perform left VEIL. Incision of $1 \mathrm{~cm}$ on the vertex of the Scarpa's triangle with insertion of trocar of $10 \mathrm{~mm}$; insertion of trocar of $5 \mathrm{~mm}$ in medial and lateral aspect and insufflation with C02 was carry out. Repair points: great saphenous vein and its tributaries (superficial epigastric vein, superficial circunflex iliac vein, lateral accesory saphenous vein, left pudenda vein) was identified. Inguinal lymphadenectomy was performed over the fascia and below the inguinal ligament, then radical hemivulvectomy was performed.

\section{CONCLUSION}

VEIL is an alternative to SLN, less morbid than ELND and feasible as a node dissection of VMM.

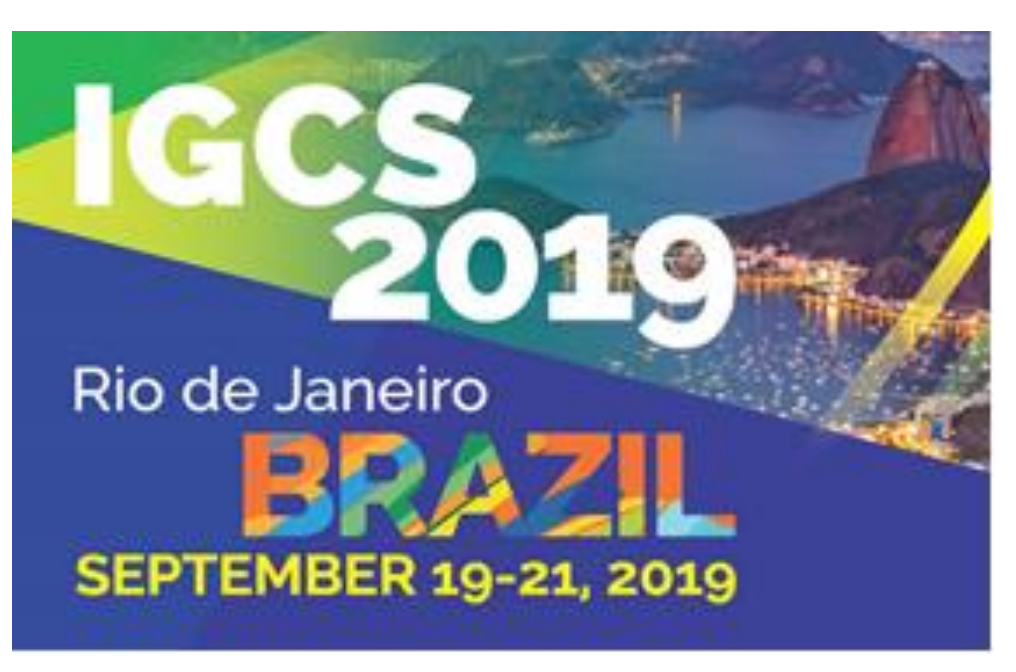

\section{Fundación} Universitaria Sanitas Organización Sanitas Internacional 